\title{
ROBOT BASED INTERACTIVE GAME FOR TEACHINg ARABIC SPELling
}

\author{
Ghada Alsebayel and Jawad Berri \\ Department of Information Systems, College of Computer and Information Sciences \\ King Saud University, Riyadh, Saudi Arabia
}

\begin{abstract}
Game based learning is becoming a widespread technique used to enhance motivation, involvement and educational experience of learners. Games have the potential to support educational curricula when designed effectively. In this work, an educational game to teach Arabic spelling to children is proposed. The game consists of two main parts; a robot and a desktop application. The robot is connected to the desktop application to form the complete game. Our mere focus is to develop an interactive, adaptive game to motivate students and let them interact joyfully in their environment while learning simple Arabic spelling rules. The interaction was implemented through designing an interaction model between the user and the robot, where the robot responds to user input with appropriate facial expressions and vocal statements. On the other hand, adaption and intelligence of the game is done through utilizing the nutshell of expert systems' framework with some alterations. Our proposed game is based on the curriculum of Saudi Arabia in elementary schools. It is anticipated that the deployment of robot-based games in the classroom will advance students' engagement and enthusiasm about learning Arabic spelling.
\end{abstract}

\section{KEYWORDS}

Game based learning, Arabic spelling, Arduino.

\section{INTRODUCTION}

Technology aided education means the application of technology to boost up knowledge acquisition and retention among students. Nowadays, we need technology presence in each classroom because it is the pen and paper of our time. Before exploring how to utilize such techniques, it is worthy to mention that the development of any language skills is composed of four gears; reading, writing, listening and speaking. The motivation of this research is to develop a system that focuses on enhancing writing language skills for Arab children, specifically spelling.

Arabic is a Semitic language that has many unique properties; it is very rich in vocabulary and has a rich phonology system. The morphological pattern system is unique where words are derived from triliteral roots. Words can always be traced back to their roots, which is then transferred into all different patterns (awzaan) to give different shades of meanings from the original meaning. Many words are syntactic. The diacritic marks in some cases control the syntactic position of the word.[1]

In recent years, some studies noted that Arabic writing skills of students in different educational levels are degrading. According to a field study with a sample of 300 students in Riyadh by AlShaalan [2] designed to measure the level of linguistic achievements of students in the sixth grade and the first year of intermediate school, it was found that there is an undeniable weakness 
in spelling skills among students. Furthermore, based on personal observations, many users of social media are making spelling and grammar mistakes when they express their thoughts through writing in Arabic. Another image of abusing the language, is when college level students make spelling or grammar mistakes in their written exams. Educators and language specialists are worried about this noticeable phenomenon that requires some corrective measures to be undertaken.

This research is a contribution to such corrective measures to enhance Arabic writing skills among Arab children speakers with the assistance of technology. As technology is being integrated more and more with every aspect of our lives, many technological tools and techniques are employed in the educational process to make learning more efficient. One particularly interesting method of teaching that could benefit from technology is; learning by playing. Playing is often defined as an activity done for one's own sake, characterized by means rather than ends. As children invest time and energy in play, there are opportunities for learning when they do play [3]. By assimilating the concept of 'learn by play' with technology, we aim to develop a fun, interactive, adaptive game for teaching Arabic spelling. The nature of this research paradigm is multidisciplinary, investigating many research areas such as; human computer interaction, user experience, persuasion, gaming, artificial intelligence, robotics and education. The basic concept is to build a robot based, interactive, adaptive game for teaching Arabic spelling. Robots have an amazing ability to create instructional method motivating students, encouraging innovation, creating more powerful interaction models, adding a joyful experience in a classroom, inspiring students to think outside the box, and finally preparing students for future trends in IT.

The contribution of this research is to design and implement an interactive and adaptive educational game to teach Arabic spelling. By designing the system to be adaptive, it will propose questions relating to specific Arabic spelling rules based on the detected weakness a child might have. The scope of this is based on the curriculum of Saudi Arabia for primary grades.

\section{BACKGROUND AND LITERATURE REVIEW}

Educational games are designed to help people understand concepts, learn domain knowledge, and develop problem solving skills as they play games [4]. While educational games can be designed to aid users in different age groups learn any field, this work is mainly focused on educational games for young children. It is a noticeable phenomenon that children spend a lot of time playing, especially computer-based games. If that time can be exploited for teaching them some concepts, it is anticipated that their learning outcomes will increase drastically. However, there is limited direct evidence of the effect of computer-based games on classroom learning [5].

In an attempt to bridge that gap, a randomized controlled trial by David J Miller and Derek P Robertson, was conducted on a population of 634 primary school students ages between 10-11 from thirty-two schools across Scotland [5]. The sample was divided into two sub-groups; controlled and experimental. Students in experimental schools were permitted to use game console for 20 minutes each day running a brain training game while the controlled sample continued their normal routine. The trail lasted 9 weeks. By the end of the trial, the following benefits were found: i) Both groups have improved in terms of computational speed and accuracy, however, the rate of improvement in the controlled group was significantly faster, and ii) There was a minor but statistically substantial improvement in the attitude towards school among students in the controlled group. Meaning that students in the controlled group were more enthusiastic about attending school [5].These two findings shape the motivation of this research. Even though, the previously mentioned study was directed to evaluate the computation skills of 
students after using computer-based gaming, other evidence was found in the literature supporting the same outcomes when examining language skills. A study by Emilija Stojmenova Duh and Natasa Koceska proposed an application (Azbuka) developed to teach children how to write Cyrillic letters. The research investigated many design challenges as well as an evaluation of the impact of the newly developed tool on acquiring the skill of writing Cyrillic letters among the sample understudy. It was found that the average time required to write a Cyrillic letter after using the application was decreased when compared to the average time required to write a Cyrillic letter using classical method [6].

\subsection{Educational Games Design and Development Methodologies}

Game design and game development are two terms that might be used interchangeably. However, if we want to differentiate them, we would say that game design encompasses all the activities of concept creation, storylines, mechanics...etc. While game development involves the steps of making the game, animation, sounds, code...etc. When designing a game many challenges arise. In addition to intense coding required for game engine, middleware, interface, sounds, animation and game production, designers must also think about how to make the game engaging and amusing. Such challenges are magnified when we talk about educational games since more advanced design considerations are required as we try to combine both the educational factor and the entertainment factor.

Despite the difficulties, many frameworks in the context of designing educational games were proposed. According to Embi et al. [7], who proposed a theoretical Edutainment Environment Framework, the difficulty for a child to learn a certain concept is composed of two elements; motivation and psychological need. The motivation necessitates catching the child's attention and attracting him/her to spend time on some activity. While psychological need means triggering the child's cognitive ability to build the knowledge. Practices for game design includes utilization of storytelling, animation, feedback and other game design methods when creating the educational game by game designers. The educational game can then be used by educators to assist the learning process either in collaborative or individual manner. Consequently, the "edutainment" environment is created.

Another model for educational games development is the game object model GOM. GOM was originally proposed by Amory et al. and Amory [8]. The model is loosely based on the objectoriented concepts such as; polymorphism, encapsulation, inheritance, abstraction...etc. Components of an educational game are usually related and dependent on each other, yelling some complexity in the game design and development. As a solution, using the metaphor of object orientation permits viewing the components of an educational game as correlated objects, making the analysis and design easier.

Another contribution by Said [9] proposed the Engaging Multimedia Design Model for Children, where he presented five design factors contributing to creating an engaging model for a child. These factors include: i) Simulation interaction: permitting the child to react on behalf of someone else like role playing, ii) Construction interaction: permitting a child to construct or build something, iii) Immediacy: where every action by the child has an effect, and can be reflected on the system, iv) Feedback: every action by the child has a reaction by the system, and v) Goals: are obvious and are either set for the child or set by him/her when no external motivation is present. In our implementation, we utilized immediacy and feedback in our design. The following sections will elaborate on the proposed game design. The fact that educational games have the potential to enhance learning outcomes, intrigues us to further explore the effect of leveraging advanced technologies, such as; robotics as a part of the educational game framework. 


\subsection{Robots in Classrooms}

For fairly a long time now, robots have been known to serve in many domains such as the industry, engineering, and rescue. However, the usage of robots has been extended to include wider domains in recent years, including the education sector. The integration of robotics in the educational system has opened-up many research areas as well as practical potentials. According to Beran et al., children are now spending more time playing with advanced technological devices during their free time [10]. As a result, studies were conducted to examine the influence of using robotics in the development of cognition, language, interaction, social and moral skills of children. In our review, we will be focusing on the literature addressing language skills development using robots.

Based on Chang et al., robots can be used to create a fun, interactive, engaging experience for children developing language skills [11]. This finding lines-up with the quantitative study completed by Young et al. A sample of 68 young children in elementary school (Grade 3-4) were under study; among them 6 students ( 2 boys and 4 girls) were selected as a focus group to evaluate their attitude towards integrating tangible learning companions in learning English conversation. The findings indicates that $95 \%$ of students had positive attitude towards tangible learning technologies, which includes robots. It contributed positively to making students more active and welling to engage in learning activities [12]. Another study by Sugimoto was applied on 25 children in elementary school aging 11-12 years old, participants experimented story creation with GENTORO robot and handheld projector. Result showed that children were highly engaged and acted in a coordinated manner [13]. Additionally, Chen, Quadir and Teng conducted anecdotal case studies on 5 elementary school students where they tested the impact of using a robot, a computer and a book for teaching English language. They concluded that robots can enhance the concentration in learning the language [14].

Commercially, Kubo is an application of educational robots for children. Kubo is a robot by Tom's Hardware Inc. aiming to teach young children basics of spelling and logic. Kubo is puzzlebased teaching toy for children aged 3 years old and above. The packaging consists of a small robot and card tags. The robot has two wheels to roll over the cards and read their content. The idea behind Kubo is to utilize radio frequency identification RFID in the cards permitting the child to assemble words then checking his/her spelling. Kubo has other features teaching logic and programming, however, for the purpose of our research only its teaching capabilities for languages were studied. Even though Kubo has potentials to accelerate language learning, its interaction model remains limited. It does not incorporate speakers or headphones for vocal communication. It does not provide extensive feedback to user input indicating whether user input is correct or not due to the fact its targeted user group is too young.

\subsubsection{Arduino for Robotics}

Arduino is an open source platform that can be used for developing electronic projects. It consists of physical circuit board that can be programmed and a software integrated development environment IDE. The initial idea of this work was inspired by woodyrobo [15]. Woodyrobo is an interactive game to teach spelling of simple English words. In the implementation, Arduino was used with a mobile application. Even though the interactive aspect of the game can be enjoyable and attracting to children, the system still lacks some key functionalities such as being expandable and adaptive. Moreover, the intelligence aspect is completely neglected, it only supports 7 words. We aimed to overcome these limitations in our implementation. 
International Journal of Artificial Intelligence \& Applications (IJAIA) Vol.10, No.6, November 2019

Next part of the literature review will be explicitly focusing on applications of different technologies to implement educational games for teaching Arabic language and spelling checking.

\subsection{Educational Games for Teaching Arabic}

Although the literature is very rich when it comes to game-based learning for teaching different languages leveraging technology, there aren't many such learning tools for Arabic [16] specially designated for young children.

Erradi et al. have published their experience designing a mobile multimedia supported platform to teach Arabic spelling and vocabulary in an intuitive fun manner. The system was not designated for young children. They took advantage of the touch capabilities in mobile and handheld devices to make the game interactive [16]. Another paper was published by Belkhouche et al. [17], addressing the design and implementation of an HTML5 based game to teach Arabic language skills to young children. Firstly, they surveyed 100 university students about their outlook on educational games, results showed that overall perception on educational games was positive; educational games were found to be an important pillar of the educational curricula. In advanced stages of their search, four major components contributing to game-based learning were identified; content (curriculum), knowledge structure (concept mapping), learning stagey (gameplay), and learning process (assessment). They analyzed primary school Arabic language textbooks in UAE to generate the learning content. Conceptual mapping was then used to model students' cognitive structure, which Consists of the following levels: i) Level one: students are taught the concept of alphabet, once they have mastered it they can move to level two, ii) Level two: students are taught the concept of words, spelling and pronunciation, once they have mastered it they move to level three, Level three: students are taught the concept of a simple sentence. Our work extends their efforts to applying these principles to robot-based gaming.

\subsection{Spelling Checkers as Knowledge Based Expert Systems}

Expert systems are an application of artificial intelligence, the basic concept behind expert systems is to mimic the abilities of a human expert in a specific field. Expert systems are designed to have decision making abilities when fed by the required knowledge. Formally an expert system is an intelligent computer program that uses knowledge and inference to solve problems that are difficult enough to require significant human expertise to solve them. There are three main components of an expert system; knowledge base, inference engine and user interface. The knowledge base is a repository of specific knowledge and rules about a certain subject; it holds objects associated with rules. Next component is the inference engine, which is the processors of the system, leveraging knowledge of the knowledgebase to draw conclusion. There are two types of inference engines: i) Deterministic inference engines: decisions by such inference engines are finite, ii) Probabilistic inference engines: decisions by such inference engines have uncertainty element associated with them [18]. One example found in the literature for utilizing expert systems as spelling checkers is Hascheck. It was built on a dictionary of the Croatian language. The initial dictionary counted less than 100,000 frequently used words. Classification and tagging algorithms were then used on the words of the dictionary. The final product was a spell checker open for all word processors and can analyze a passage of 100,000 words and response within one minute [19]. 


\section{Design Methodology}

The utilization of technology and robotics has the potential to enhance the learning experience of students. This research aims to leverage the advancement of technology to contribute to solve weakness in Arabic spelling skills among Arab speaking youth. By integrating artificial expert systems and robotics we aim to develop an interactive adaptive educational game. Throughout this chapter, the implementation methodology of the proposed system will be presented.

The literature suggests that game-based learning is efficient in guiding young children to acquire language skills. Furthermore, it advocated the integration of robotics applications in the educational system. There exist in the literature some applications for using robotics as tools for teaching language skills. However, they were not exploited to their full potentials in our the Arabic context for the following reasons: i) Robotic tools presented in the literature were experimental and mostly supporting English, ii) The adoption of technologically advanced tools in classrooms can be costly, robots presented in the literature were relatively advanced, iii) Robotics presented in the literature were not designated to teach Arabic spelling. Our proposed model and system aim to produce an affordable robot-based game for teaching Arabic spelling to bridge that gap.

There are many software development methodologies. The two most widely known are predictive and adaptive. The following figure illustrates suitable software development life cycle based on project characteristics. Most projects fall in a range between adaptive and productive SDLC [20]. In our implementation we followed an adaptive incremental approach. Hence, the game was be developed in releases, where each release incorporates new functionalities added to the pervious release. Each iteration was like a mini project. Within each iteration, several activities took place. Including; planning, analysis, design, implementation, and deployment.

The reasons for this selection is because the technology that will be used is new and unfamiliar. Moreover, incremental development methodology introduces many advantages including: i) Generating working software as early as possible during software development life cycle SDLC, ii) Being able to adopt to changes, change is not as costly as using predictive approach, iii) Receiving feedback rapidly, which allows further enhancements to be made to each release, iv) Prompting simplicity; simple solutions for complex situations. The game has been developed in releases where the first release included a single lesson of Arabic spelling rules based on the curricula of Saudi Arabia. Additional functionalities were added within each further system releases.

\section{System DeSign}

Our proposed system includes two components: software and hardware. In the following section, system analysis and design of both components is presented. Hardware design explains the needed parts to build up the robot. While analyzing and designing the software aims to structure the functional requirements that will be covered by the system, software design principles, and use cases.

\subsection{Game Scenario}

The system's hardware design was concerned with connecting the electrical parts then building a shield to produce a functioning robot that could present encouraging gestures for the child based on to his/her performance. On the other side, the system's software component was mainly focusing on developing the backend code to trace users' spelling weakness and suggest words 
accordingly. In the last stage of the implementation, these two major components were integrated to produce the final product.

The robot/child interaction scenario is as follows: the robot pronounces a word for the child to spell it. The child should spell the word using a keyboard. Once the child finishes inputting the letters, he/she should press the enter key button to indicate the end of input. The robot responds to user's input with a facial and vocal expressions. The robot will utilize the servos to frown if the answer is wrong and nod if the answer is correct. A suitable message will be spoken to the child in both cases.

\subsection{Robot Design}

In designing the robot, we used affordable material to produce a prototype as a proof of concept. The following hardware components were used: i) Arduino Uno, ii) 1 Standard Servo, iii) LED Matrix (16x2), iv) Breadboard, wires, power supply.

Arduino Uno is a microcontroller board for building digital devices and interactive objects that are used to form the basis of the robot. In addition, servos are used to create movements of the robot's head to encourage the child when he/she make correct answer. The interaction between the child and the robot is done through keyboard and a screen. In the initial release we built a desktop application to serve as means of communication between the robot and the user. The same concept applies for a mobile application. The sequence of interaction is shown in the following figure.

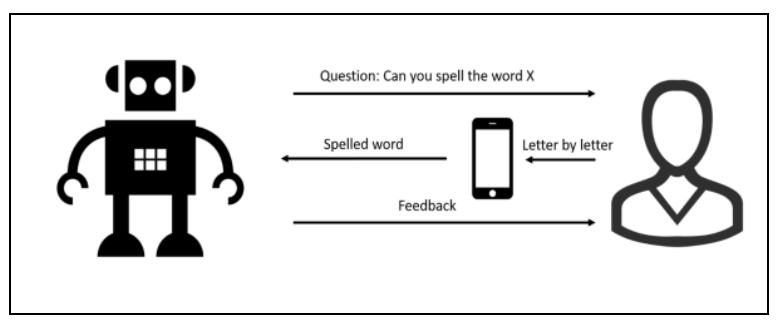

Figure 1: Interaction Model

The prime users of the software are Arab speaking children aiming to enhance their spelling skills. Additionally, a knowledge acquisition subsystem can be developed in later releases to obtain knowledge from teachers and extend the content of the game.

In our implementation we integrated the following design features to enhance the child experience when learning:

- Interactivity: an educational game should be highly interactive. The reason is that the higher the interactivity of the game is, the higher engagement of the user will be accomplished, thus more enjoyment, more time spent on the game and ultimately, more knowledge is gained.

- Adaptivity: and educational should attain high adaptivity. Adaptive teaching is a way of informing users' learning by personalizing and facilitating it in ways that meets every individual's needs.

- Guidance by goals and rules: educational games are always guided by goals and rules complying with the subject understudy.

- Continuance feedback: the educational game should give instant feedback to the actions of the user. 
- Sensory stimuli: In physiology, a stimulus (plural stimuli) is a noticeable alteration in the internal or external surroundings. The ability of an organism or organ to respond to external stimuli is called sensitivity. [21]

When designing video game, we aim to trigger stimulus and imagination by adding voices, animations and movements to make the game entertaining. The same is applicable for educational games. Table 1 summarizes how these game design elements are integrated in the implemented system.

Table 1: Game Design Elements

\begin{tabular}{|c|c|}
\hline $\begin{array}{ll}\text { Game } & \text { Design } \\
\text { Element } & \end{array}$ & Ways Design Elements are Integrated in The Game \\
\hline Interactivity & $\begin{array}{l}\text { 1- } \quad \text { Robot Facial expressions corresponding to user input. } \\
\text { 2- } \\
\text { 3- }\end{array}$ \\
\hline Adaptivity & $\begin{array}{l}\text { 1- System proposing words based of the performance of the child. } \\
\text { 2- System advancing child to next levels when he/she meets some } \\
\text { criteria set by teacher. }\end{array}$ \\
\hline Guidance by goals & $\begin{array}{l}\text { 1- The short-term goal is to spell the word correctly. } \\
2-\quad \text { The long-term goal is to advance to the next level. }\end{array}$ \\
\hline Continuance feedback & $\begin{array}{ll}\text { 1- } & \text { Robot facial expressions. } \\
\text { 2- } & \text { Verbal messages. } \\
\text { 3- } & \text { Reflecting child's input on LED screen. }\end{array}$ \\
\hline Sensory stimuli & $\begin{array}{l}\text { 1- Triggering both visual and verbal stimulus by voice and facial } \\
\text { expressions. }\end{array}$ \\
\hline
\end{tabular}

\subsection{Framework}

The framework used to develop the system includes the following components:

Knowledge base: the knowledge base serves as the dictionary of the game containing all the words encountered in the game.

Inference engine: the inference engine is the component of our system that applies the spelling rules on the knowledge base. In this release, we tackled one of the most basic and important spelling rules in Arabic, the rule of sun and moon letters “ قاعدة الحروف الثمسية و القمرية ". The Arabic alphabet consists of 28 letters, which are classified into 14 sun letters and 14 moon letters. The classification of the letters is based on how these letters influence the pronunciation of the definite article at the beginning of the word.

In our implementation, a binary classifier was built to classify any word based on the following classification rule:

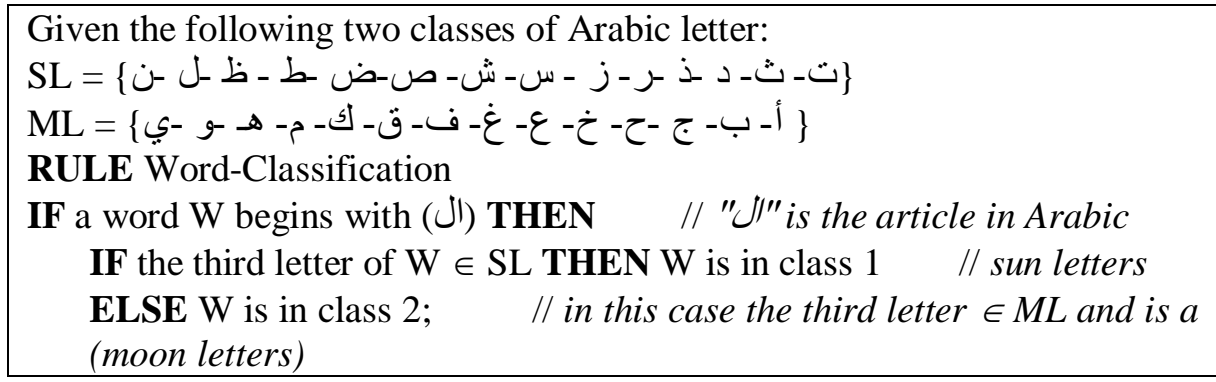


Binary Classification would generally fall into the domain of supervised learning since the training dataset is labelled. Moreover, as the name suggests it is a special case where there are only two classes. In Our implementation, the binary classifier is rule based.

User interface: in our system the user interface will be presented via a robot and a smart application. The robot was integrated to maximize both amusement and interaction elements of the game.

Question Generator: is an additional component which is responsible for producing questions to the user in the form of "can you spell the word x?". An important feature of the question generator is its adaptivity. In other words, it proposes questions to the user based on his/her former performance. For instance, if it was detected that the user had a weakness in a specific spelling rule, he/she will be presented with a suitable explanation. Then other questions related to the rule in question will be presented. A user will be able to progress to the next level only if a user has met some specific criteria set by the teacher (for example 5 correct answers on the same rule).

The user can respond to the question "Can you spell the word $\mathrm{x}$ ?" with a query "Is my spelling of x correct?". The system responds to the query with an advice; either:

1- Your spelling is correct advance to the next level.

2- Your spelling could be improved you have to try again. The system keeps proposing questions on the same spelling rule until some criteria is met.

Knowledge acquisition subsystem: this subsystem is intended to be used by the teacher to extend the levels of the game by adding new spelling rules and lessons. It was not included in the initial release. However, we intend to develop a knowledge acquisition subsystem in the upcoming releases. The following figure conceptualizes system components.

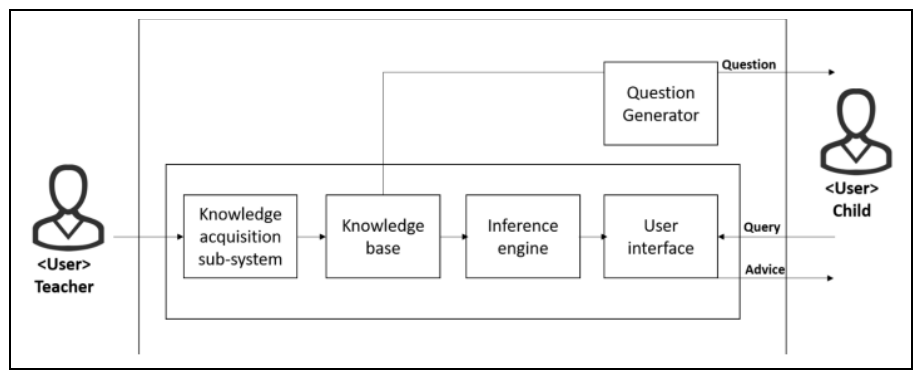

Figure 8: Proposed Framework

Table 2 shows a sample system user based on a testing session.

\begin{tabular}{|c|c|c|c|}
\hline $\begin{array}{l}\text { Question } \\
\text { generated by } \\
\text { the system }\end{array}$ & $\begin{array}{l}\text { User } \\
\text { response }\end{array}$ & $\begin{array}{l}\text { System } \\
\text { interaction } \\
\text { advice }\end{array}$ & System action \\
\hline 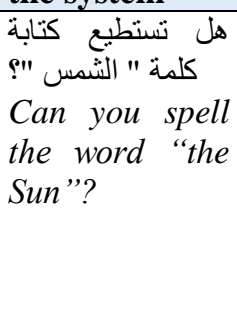 & $\begin{array}{l}\text { Wrong } \\
\text { Wrolling of } \\
\text { spell } \\
\text { the word } \\
\text { "the sun" } \\
\text { because it is } \\
\text { missing the } \\
\text { second letter }\end{array}$ & $\begin{array}{l}\text { حاول مرة أخرى } \\
\text { Try again }\end{array}$ & $\begin{array}{l}\text { The system detects that the child } \\
\text { is having difficulty with the sun } \\
\text { letters (الثلام الثمسية) therefore } \\
\text { proposes more questions on that } \\
\text { rule }\end{array}$ \\
\hline
\end{tabular}


International Journal of Artificial Intelligence \& Applications (IJAIA) Vol.10, No.6, November 2019

\begin{tabular}{|c|c|c|c|}
\hline 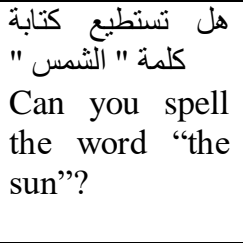 & $\begin{array}{l}\text { Correct } \\
\text { spelling of } \\
\text { the word } \\
\text { "the sun" }\end{array}$ & $\begin{array}{l}\text { مثناز ، أحسنة صحيحة } \\
\text { Excellent, } \\
\text { Good job. } \\
\text { Correct } \\
\text { answer }\end{array}$ & $\begin{array}{l}\text { The system detects that the child } \\
\text { has written the word correctly. }\end{array}$ \\
\hline 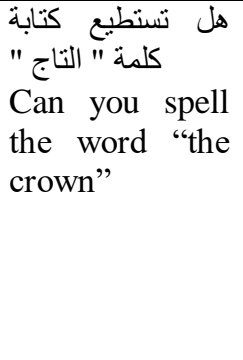 & $\begin{array}{l}\text { الناج } \\
\text { Correct } \\
\text { spelling of } \\
\text { the word } \\
\text { "the crown" }\end{array}$ & $\begin{array}{l}\text { ممتاز ، أحسنة صحيحة } \\
\text { Excellent, } \\
\text { Good job. } \\
\text { Correct } \\
\text { answer }\end{array}$ & $\begin{array}{l}\text { After the user completes a set of } \\
\text { words correctly, he/she can be } \\
\text { transformed to next level where } \\
\text { he/she is taught another rule. } \\
\text { The passing criteria (i.e. how } \\
\text { many words of a certain rule } \\
\text { should a child spell correctly } \\
\text { before moving to the next level) } \\
\text { is set by the teacher. }\end{array}$ \\
\hline $\begin{array}{l}\text { هل تلمنة " القمر " كتابع } \\
\text { Can you spell } \\
\text { the word "the } \\
\text { moon" }\end{array}$ & $\begin{array}{l}\text { l القمر } \\
\text { Correct } \\
\text { spelling of } \\
\text { the word } \\
\text { "the moon" }\end{array}$ & $\begin{array}{l}\text { ممثاز ، أحسنت صحيحة } \\
\text { Excellent, } \\
\text { Good job. } \\
\text { Correct } \\
\text { answer }\end{array}$ & $\begin{array}{l}\text { The loop is repeated for the } \\
\text { moon letters ( اللام القمرية) }\end{array}$ \\
\hline
\end{tabular}

The selected architecture of the system is layered. The following diagram shows the architectural design of system components in the first release. The system is composite of 4 layers; the presentation layer is represented by the robot and its facial expressions and vocal interactions. The business layer consists of generators of these vocal and facial responses based on user input. The persistence layer holds key modules; question generator which is responsible for proposing spelling questions based on the child performance and the spelling rule he/she is currently learning, spelling corrector which is responsible for determining whether user input is correct or wrong, and deficiency detector which is responsible for determining the weakness a child might have. This information is useful for the next iteration of questions, to address the issues he/she might have. Lastly the knowledge base and inference engine containing dictionary and spelling rules.

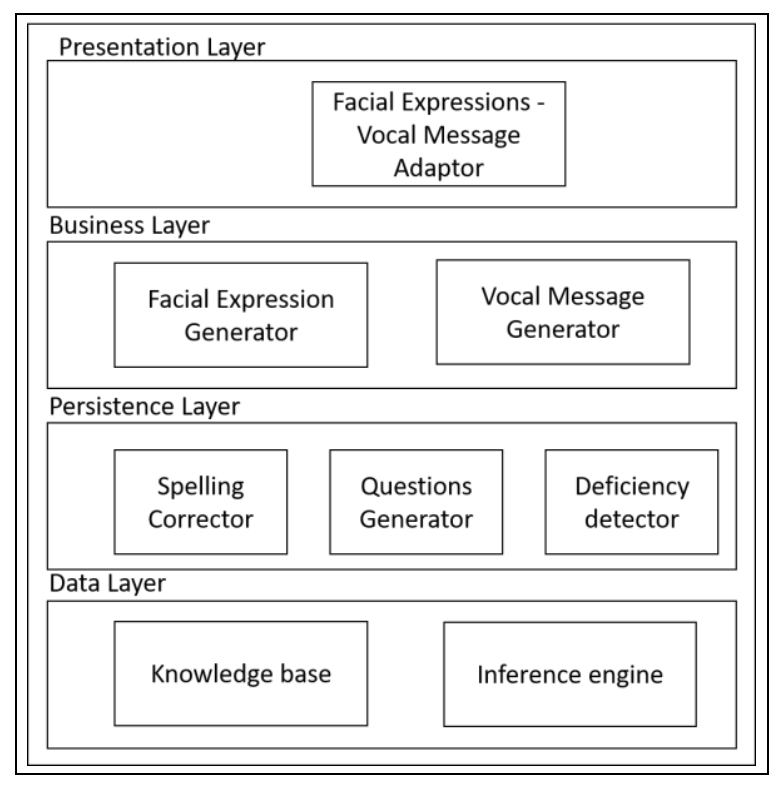

Figure 10: System Architecture 


\section{SYSTEM IMPLEMENTATION}

This section presents in detail how the implementation of the system was carried on. Following the iterative and incremental development methodology, our system was implemented in releases, where each release focuses on building certain set of functionalities. After each component was built and tested, integration of all components was done.

The following sections show the implementation of the presentation layer, where user interfaces were executed. Furthermore, the implementation of the business layer is examined to show how facial expressions of the robot were implemented. Additionally, and most importantly, the persistence layer is introduced showing how each of the subcomponents, namely; question generator, spelling corrector and deficiency detector are implemented and integrated. Lastly, the dataset of the application is illustrated.

\subsection{Graphical User Interface}

In the initial release, we developed a desktop application as means for interaction between the user and the robot. The software was implemented using Visual Studio as an integrated development environment and $\mathrm{C \#}$ as a programming language. Firstly, the interfaces were designed stressing on simplicity and clarity since the system is meant to be used by kids. The navigation has been designed to be clear and easy. Friendly icons and visual descriptors were used. The following figures illustrates some of the application's interfaces.

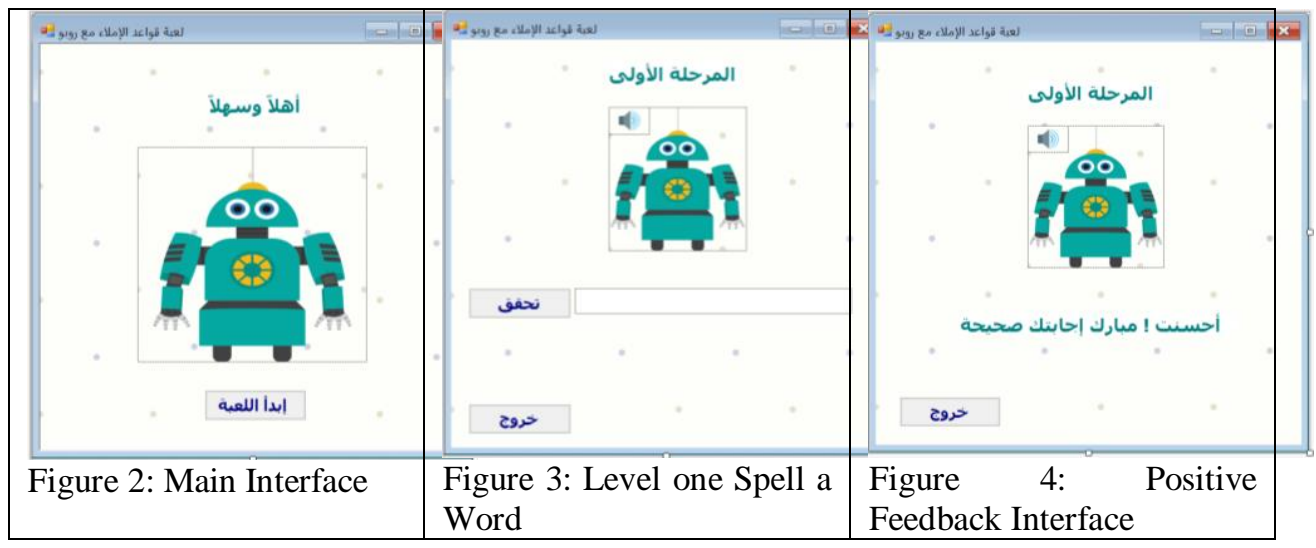

The main interface of the application (Fig. 11) displays a button to start the game as well as playing voice in the background to welcome the player. The second interface (Fig. 12) displays the player's level. Additionally, a word will be pronounced for the player to spell. If the player wants to listen to the word again, he/she can press the speaker's icon. Using a keyboard, a player can input the word then press check button. The third interface (Fig. 13) represents a positive feedback to player's input. In case the entered word is spelled correctly this interface will be displayed as well as a positive response of the robot. The robot will node and show a smelly face, this will be illustrated in the hardware implementation section.

\subsection{Hardware Components}

For the purpose of completing the implementation phase, a proof of concept prototype was developed to represent the robot. Arduino Uno, which is a microcontroller board, was the center of our prototype. It has 14 digital input/output pins (of which 6 can be used as PWM outputs), 6 analog inputs, a $16 \mathrm{MHz}$ quartz crystal, a USB connection, a power jack, an ICSP header and a 
International Journal of Artificial Intelligence \& Applications (IJAIA) Vol.10, No.6, November 2019

reset button. Arduino was connected to two 8X8 LED matrix components to represent the eyes of the robot. A standard servo was used to model neck movement of the robot.

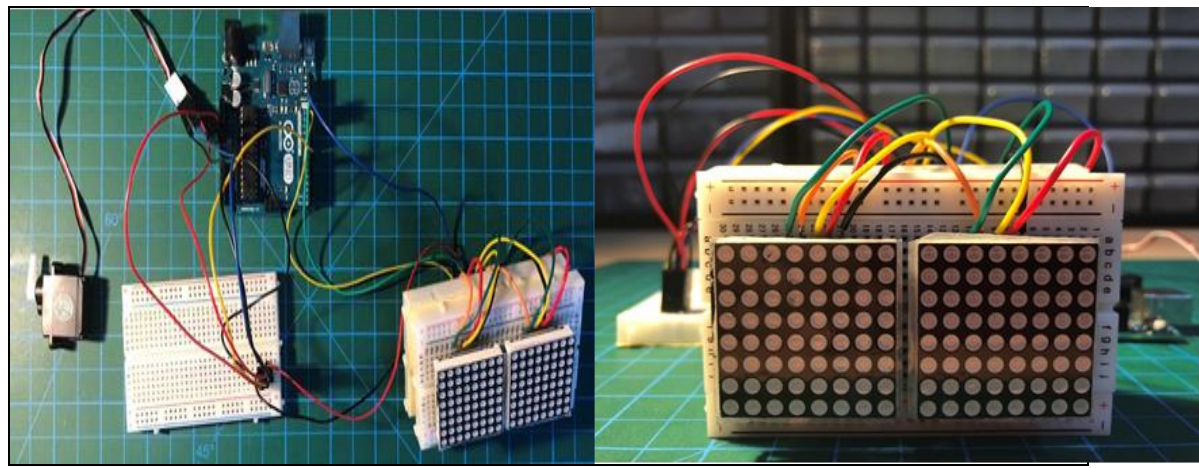

Figure 5: Used Material

The following table illustrates how the assembly of the hardware was done:

Table 2: Arduino Assembly

\begin{tabular}{|l|l|l|}
\hline Arduino & LED & Servo \\
\hline Ground & Ground & Ground \\
\hline V5 & V5 & V5 \\
\hline Pin 6 & - & Servo \\
\hline Pin 11 & CS & - \\
\hline Pin 12 & CLK & - \\
\hline Pin 13 & SDI & - \\
\hline
\end{tabular}

Where SDI is the serial data input pin, CS is the chip select that turns on tristate outputs on data pins, or signifies that inputs are valid and can be latched, stored or processed. CLK is a connection for a square wave signal that synchronizes systems.

After connecting the hardware, Arduino 1.8.5. The open-source Arduino Software (IDE) was used to develop a code to control the robot's expression. A total of three facial expressions were developed; happy expression, resting face and a sad expression. Furthermore, to make the robot more realistic a blinking method was also implemented. Figure 15 shows the system components and the graphical user interface.

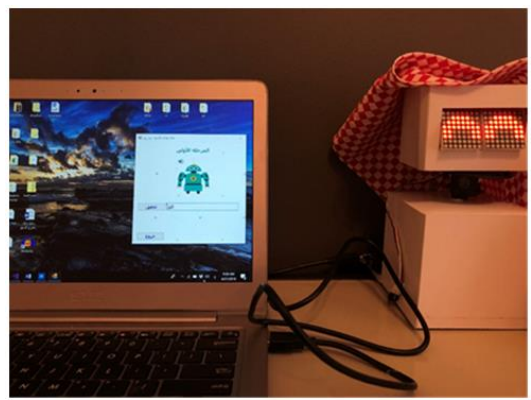

Figure15: System User Interface. 
International Journal of Artificial Intelligence \& Applications (IJAIA) Vol.10, No.6, November 2019

\subsection{Persistence Layer}

\subsubsection{Questions generator}

This component is the first of the components in the persistence layer. The purpose of this component is to propose a question for the player, word to spell. Table 4 shows the pseudo code of the function.

Table 3: Questions Generator Pseudo Code

\begin{tabular}{|l|l|}
\hline Questions Generator \\
\hline Pre-condition & None \\
\hline Post- condition & $\begin{array}{l}\text { A word will be selected from the knowledge base and } \\
\text { pronounced for the player. }\end{array}$ \\
\hline Pseudo code & $\begin{array}{l}\text { Begin } \\
\text { Index = Generate a random number; } \\
\text { Retrieve word [Index]; } \\
\text { Retrieve Sound [Index]; } \\
\text { Pass Sound [Index] to Speaker; } \\
\text { End }\end{array}$ \\
\hline
\end{tabular}

\subsubsection{Spelling corrector}

This is the second component in the persistence layer. The purpose of this component is to check whether the entered word is correct. Table 5 shows the pseudo code of the function.

Table 4: Spelling Corrector Pseudo Code

\begin{tabular}{|c|c|}
\hline \multicolumn{2}{|c|}{ Spelling Corrector } \\
\hline Pre-condition & Player has entered a word in the textbox. \\
\hline Post- condition & $\begin{array}{l}\text { The robot will show either positive or negative feedback } \\
\text { depending on player's input. }\end{array}$ \\
\hline Pseudo code & $\begin{array}{l}\text { Begin } \\
\text { Answer = Read player's input; } \\
\text { If (Answer == word [Index]) } \\
\text { \{ } \\
\text { Show positive feedback; } \\
\text { Move to next level; } \\
\} \\
\text { Else } \\
\text { Detect deficiency; } \\
\text { End }\end{array}$ \\
\hline
\end{tabular}

\subsubsection{Deficiency detector}

This component is the third component in the persistence layer. It is a very essential component which aims to detect what exactly is the deficiency the player is having. For this release of the application the rule of sun and moon letters in Arabic “ قاعدة الحروف الثمسية و القمرية "was implemented. The following illustrates pseudo code for the function. 
Table 5: Deficiency Detector Pseudo Code

\begin{tabular}{|l|l|}
\hline Deficiency Detector \\
\hline Pre-condition & Entered word was spelled incorrectly by the player. \\
\hline Post- condition & The correct spelling will be presented to the player. \\
& A new word will be generated for the player within the same \\
& spelling rule detected.
\end{tabular}

Each time a player makes a spelling error in one spelling rule, his/her error will be corrected and for the next three iterations, new words of the same rule will be proposed. The reason for selecting three trials was based on experts' judgment of teachers in elementary schools.

\subsection{Data Layer}

In the first release of the game, the lexicon was built based on Saudi Arabia's curriculum the first lesson of $2^{\text {nd }}$ grader's Arabic book(لغتي الخالدة) Page\#30, 28 words were selected and categorized into two classes each of 14 words. The first class represents sun letters and the second class represents moon letters.

The following table summarizes words currently available in the lexicon.

Figure 6: Game's Lexicon

\begin{tabular}{|c|c|c|}
\hline$\#$ & Class 1 (Sun letters) & Class 2 (Sun moon) \\
\hline 1 & الأمر (the command ) & الشمس (the sun) \\
\hline 2 & البرتقال ( the orange) & التفاح (the apple) \\
\hline 3 & الجنة (the heaven) & الثمر ات (the fruits) \\
\hline 4 & (the life) & الدين (the religion) \\
\hline 5 & الخس (the lettuce) & الرمان(the pomegranate) \\
\hline 6 & العيون (the eyes) & الز هور (the flowers) \\
\hline 7 & الغيوم (the clouds) & السماء (the sky) \\
\hline 8 & الفارس (the knight) & الصباح (the morning) \\
\hline 9 & القائد (the leader) & الضحى (the morn) \\
\hline 10 & الكريم (the generous) & الطين (the mud) \\
\hline 11 & الموز (the banana) & الظلام (the dark) \\
\hline 12 & الهدهد (the hoopoe) & الليل (the night) \\
\hline 13 & الوعد (the vow) & النهار (the day) \\
\hline 14 & اليمين (the right) & الذئب (the wolf) \\
\hline
\end{tabular}




\section{SYSTEM Evaluation}

In order to check whether the actual results meets the expected results many tests were conducted to validate and verify the game. Unit testing was firstly conducted; the following section shows test cases for each part of the system. Then, after integrating all components, integration testing was performed. For the purpose of evaluating the game, the accuracy of the classifier was measured.

\subsection{Unit Testing}

In this section the test cases examined during unit testing is presented. The testing process was conducted in two phases; testing the software side and testing the hardware side. Tables 7 and 8 present some of the tests done.

Table 6: Unit Testing for the Software

\begin{tabular}{|c|c|c|c|c|c|c|c|c|c|}
\hline \multirow{2}{*}{$\begin{array}{l}\mathrm{I} \\
\mathrm{D}\end{array}$} & \multirow{2}{*}{$\begin{array}{l}\text { Name of } \\
\text { the } \\
\text { function }\end{array}$} & \multirow{2}{*}{$\begin{array}{l}\text { Objectiv } \\
\mathrm{e} \text { of the } \\
\text { function }\end{array}$} & \multirow{2}{*}{$\begin{array}{l}\text { Test } \\
\text { data }\end{array}$} & \multirow{2}{*}{$\begin{array}{l}\text { Test case } \\
\text { complexit } \\
\text { y }\end{array}$} & \multirow{2}{*}{$\begin{array}{l}\text { Expected } \\
\text { results }\end{array}$} & \multicolumn{3}{|c|}{ Actual result } & \multirow{2}{*}{$\begin{array}{l}\text { Pass } \\
\text { ? }\end{array}$} \\
\hline & & & & & & Cycle\#1 & $\begin{array}{l}\text { Cycle\# } \\
2\end{array}$ & $\begin{array}{l}\text { Cycle\# } \\
3\end{array}$ & \\
\hline 1 & $\begin{array}{l}\text { Generate } \\
\text { Question }\end{array}$ & $\begin{array}{l}\text { To } \\
\text { pronounc } \\
\text { e a a } \\
\text { random } \\
\text { word for } \\
\text { the } \\
\text { player }\end{array}$ & $\begin{array}{l}\text { Non } \\
\mathrm{e}\end{array}$ & Simple & $\begin{array}{l}\text { A word is } \\
\text { pronounce } \\
\mathrm{d} \text { for the } \\
\text { player }\end{array}$ & $\begin{array}{l}\text { اللئل } \\
\text { (the } \\
\text { night) }\end{array}$ & $\begin{array}{l}\text { الثمس (the } \\
\text { sun) }\end{array}$ & $\begin{array}{l}\text { الهدهد } \\
\text { (the } \\
\text { hoopoe } \\
\text { ) }\end{array}$ & Pass \\
\hline 2 & $\begin{array}{l}\text { Correct } \\
\text { Spelling }\end{array}$ & $\begin{array}{l}\text { To } \\
\text { validate } \\
\text { player's } \\
\text { input for } \\
\text { الثنمس }\end{array}$ & س الثه & Simple & $\begin{array}{l}\text { The word } \\
\text { should be } \\
\text { corrected, } \\
\text { screen } \\
\text { should } \\
\text { show } \\
\text { encouragin } \\
\text { g message }\end{array}$ & $\begin{array}{l}\text { Positive } \\
\text { feedbac } \\
\mathrm{k} \\
\text { interfac } \\
\mathrm{e} \quad \text { is } \\
\text { presente } \\
\mathrm{d}\end{array}$ & & & Pass \\
\hline 3 & $\begin{array}{l}\text { Correct } \\
\text { Spelling }\end{array}$ & $\begin{array}{l}\text { To } \\
\text { validate } \\
\text { player's } \\
\text { input for } \\
\text { الثمس }\end{array}$ & الثم & Simple & $\begin{array}{l}\text { The word } \\
\text { should be } \\
\text { corrected, } \\
\text { screen } \\
\text { should } \\
\text { show } \\
\text { sw الثمس }\end{array}$ & $\begin{array}{l}\text { الثنمس } \\
\text { (the } \\
\text { sun) }\end{array}$ & & & Pass \\
\hline 4 & $\begin{array}{l}\text { Detect } \\
\text { Deficienc } \\
\mathrm{y}\end{array}$ & $\begin{array}{l}\text { To detect } \\
\text { what is } \\
\text { the } \\
\text { spelling } \\
\text { rule that } \\
\text { the } \\
\text { player is } \\
\text { having } \\
\text { difficulty } \\
\text { with }\end{array}$ & القر & Difficult & $\begin{array}{l}\text { Only show } \\
\text { the correct } \\
\text { spelling of } \\
\text { the word } \\
\text { since the } \\
\text { mistake is } \\
\text { not in a } \\
\text { spelling } \\
\text { rule }\end{array}$ & $\begin{array}{l}\text { القمر } \\
\text { (the } \\
\text { moon) }\end{array}$ & $\begin{array}{l}\text { الطين } \\
\text { (the } \\
\text { mud) }\end{array}$ & & Pass \\
\hline
\end{tabular}


Additionally, unit testing was also conducted on the hardware side of the application. Test cases were driven to check the responses of the robot. The table below shows some of the test cases.

Table 7: Unit Testing for the Hardware

\begin{tabular}{|c|c|c|c|c|c|c|c|}
\hline ID & $\begin{array}{l}\text { Name of } \\
\text { the } \\
\text { function }\end{array}$ & $\begin{array}{l}\text { Objective } \\
\text { of the } \\
\text { function }\end{array}$ & $\begin{array}{l}\text { Test } \\
\text { data }\end{array}$ & $\begin{array}{l}\text { Test case } \\
\text { complexity }\end{array}$ & $\begin{array}{l}\text { Expected } \\
\text { results }\end{array}$ & Actual result & Pass? \\
\hline 1 & $\begin{array}{l}\text { Generate } \\
\text { happy } \\
\text { face }\end{array}$ & $\begin{array}{l}\text { To show } \\
\text { happy } \\
\text { facial } \\
\text { expression } \\
\text { and node. }\end{array}$ & None & Medium & $\begin{array}{l}\text { Robot } \\
\text { nodding } \\
\text { and } \\
\text { showing } \\
\text { smiley face }\end{array}$ & & Pass \\
\hline 2 & $\begin{array}{l}\text { Generate } \\
\text { natural } \\
\text { face }\end{array}$ & $\begin{array}{l}\text { To show } \\
\text { natural } \\
\text { face }\end{array}$ & None & Medium & $\begin{array}{l}\text { Robot } \\
\text { showing } \\
\text { natural face }\end{array}$ & & Pass \\
\hline
\end{tabular}

\subsection{Integration Testing}

After all the components have passed unit testing, integration between hardware and software was performed. The integration was done via connecting through serial port COM3. Table 9 shows part of the code used to check the integration on both the software and hardware sides.

Table 9: Integration testing

\begin{tabular}{|l|l|}
\hline Integration Code C\# side & Integration Code Arduino Side \\
\hline $\begin{array}{l}\text { serialPort1.Write(1); // for smiling } \\
\text { serialPort1.Write(0); // for frowning }\end{array}$ & $\begin{array}{l}\text { if (Serial.available }())\{ \\
\text { int data = Serial.read }() ; \\
\text { if }(\text { data==1) HappyFace }() ; \\
\text { else SadFace }() ;\}\end{array}$ \\
\hline
\end{tabular}

In addition, we intend to conduct observational studies to evaluate the player's engagement, enjoyment and enthusiasm about the game. Furthermore, test will be driven to evaluate knowledge acquisition and retention for players. This is planned to be done in near future.

\section{Conclusion}

Integration of game-based learning and robotics into educational systems have the potential to enhance knowledge acquisition and retention especially for young children. Throughout this paper the analysis, design, implementation and testing of an educational game to teach Arabic spelling was proposed. The proposed game has two main characteristics; adaptation and interaction. By developing an adaptive game, the system shall be able to detect the weaknesses of each individual child and propose questions accordingly. On the other hand, by adding the interaction element, the game shall be fun and engaging for the child to keep playing, hence, advance his/her knowledge. 
For future work, we aim to design and execute users' acceptance testing. Observation studies will be performed to evaluate how children interact with the game in a classroom setting. Observation of children behavior and interaction with the system will be recorded for future improvements. Furthermore, more Arabic spelling rules are planned to be implemented and integrated into the game's engine. Also, as we implemented the first release of the system, we aim to gradually build up to full release that include additional functionalities such as a dedicated module for teachers allowing them to add words to the lexicon and set flexible evaluation criteria for the players.

\section{REFERENCES}

[1] Muhammad al-Sharkawi. "History and development of the Arabic language",1st ed, Abingdon, Routledge,2016.

[2] Alshalaan Rashed "Spelling Weakness ", in Practical Methods to Treat Spelling Mistakes, 2ed, Vol 85, Riyadh, Alobeikan, 2008.

[3] Smith, P.K. and Pellegrini, A., "Learning through play. Encyclopedia on early childhood development", PP.1-6, 2008.

[4] R. v. Horn, "Educational Games," The Phi Delta Kappan, vol. 89, (1), pp. 73-74, 2007.

[5] D. J. Miller and D. P. Robertson, "Educational benefits of using game consoles in a primary classroom: A randomised controlled trial," British Journal of Educational Technology, vol. 42, (5), pp. 850-864, 2011.

[6] E. S. Duh, N. Koceska and S. Koceski, "Game-based learning: educational game Azbuka to help young children learn writing Cyrillic letters," Multimedia Tools and Applications, 2016.

[7] C. E. Zarina and H. Hussain, "Analysis of Local and Foreign Edutainment Products - An Effort to Implement the Design Framework for an Edutainment Environment in Malaysia," The Journal of Computers in Mathematics and Science Teaching, vol. 24, (1), pp. 27-42, 2005

[8] A. Amory, "Game Object Model Version II: A Theoretical Framework for Educational Game Development," Educational Technology Research and Development, vol. 55, (1), pp. 51-77, 2007.

[9] Said Norma, "An engaging multimedia design model," in 2004. DOI: 10.1145/1017833.1017873

[10] T. N. Beran et al, "Understanding how children understand robots: Perceived animism in childrobot interaction," International Journal of Human - Computer Studies, vol. 69, (7), pp. 539-550, 2011.

[11] C. Chang et al, "Exploring the Possibility of Using Humanoid Robots as Instructional Tools for Teaching a Second Language in Primary School," Journal of Educational Technology \& Society, vol. 13, (2), pp. 13, 2010

[12] S. S. Young, Y. H. Wang and J. R. Jang, "Exploring perceptions of integrating tangible learning companions in learning English conversation: Colloquium," British Journal of Educational Technology, vol. 41, (5), pp. E78-E83, 2010.

[13] M. Sugimoto, "A Mobile Mixed-Reality Environment for Children's Storytelling Using a Handheld Projector and a Robot," IEEE Transactions on Learning Technologies, vol. 4, (3), pp. 249-260, 2011. 
International Journal of Artificial Intelligence \& Applications (IJAIA) Vol.10, No.6, November 2019

[14] N. Chen, B. Quadir and D. C. Teng, "A novel approach of learning English with robot for elementary school students," in Anonymous Berlin, Heidelberg: Springer Berlin Heidelberg, 2011, pp. 309-316.

[15] "DIY a Spelling Game with an Interactive Robot", Instructables.com, 2017. [Online]. Available: http://www.instructables.com/id/DIY-a-Spelling-Game-with-an-Interactive-Robot/. [Accessed: 21Dec- 2017].

[16] A. Erradi et al, "ArabicTutor: A multimedia m-learning platform for learning Arabic spelling and vocabulary," in 2012, . DOI: 10.1109/ICMCS.2012.6320220.

[17] Belkhouche, Boumediene \& Saeed, Nafla \& Darei, Al \& Abdulla, Shamsa \& Al Mazrouei, Shamsa \& Hamdan, Shaikha \& Mandhari, Al \& Ateeq, Mouza \& Mehairi, Al. (2014). Learning Arabic With Games. . 10.5176/2251-1679_CGAT14.03.

[18] S. Liao, "Expert system methodologies and applications - a decade review from 1995 to 2004," Expert Systems with Applications, vol. 28, (1), pp. 93-103, 2005.

[19] A. Dembitz, P. Kne evi and M. Sokele, "Developing a Spell Checker as an Expert System,"Journal of Computing and Information Technology, vol. 11, (4), pp. 285, 2005.

[20] "Systems analysis and design in a changing world, 6th ed," Reference \& Research Book News, vol. 27, (5), 2012.

[21] "How does the brain process sensory stimuli? - Best Practice: Sensory", Best Practice: Sensory, 2017. [Online]. Available: http://sensory-processing.middletownautism.com/background/howdoes-the-brain-process-sensory-stimuli/. [Accessed: 17- Dec- 2017]

\section{Authors}

Ghada Alsebayel Ghada Alsebayel is a teaching assistant at King Saud University, Saudi Arabia. She received both her B.Sc. and M.Sc. from College of Computer and Information Sciences CCIS at King Saud University KSU. Ghada's research interests include data mining, data management, knowledge representation and reasoning, and their applications in health informatics. Ghada spent a year at National Guard Health Affairs, where she worked as a system analyst for the clinical information management department. In 2016, she co-founded the first summer training program at CCIS KSU, to enable young Saudi women to be better represented in STEM. The program introduces areas like coding, data science, artificial intelligence, and robotics.

Jawad Berri is an associate professor at King Saud University, Saudi Arabia. He received his Ph.D. in Computer Science from Paris-Sorbonne University in France in 1996. Jawad's research interests focus on context-aware web systems, learning technologies and natural language processing. He has been involved in many projects related to mobile learning, semantic web, automatic summarization, web information filtering and mobile agents for web information discovery. He worked as a researcher at the CNRS - the French National Research Center, the Computer Science Institute at the University of Zurich - Switzerland and Sonatrach - the Algerian Petroleum and Gas Corporation. Jawad taught in many universities around the world: The United Arab Emirates University, Khalifa University of Science Technology and

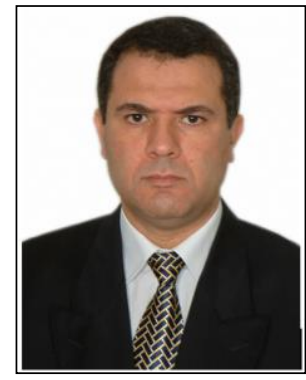
Research and King Saud University. His contributions in research projects in the industry and academia led to the publication of papers in numerous journals and conferences. Jawad is a senior member of the IEEE. 